\title{
A ADPF 153 E A OBRIGAÇÃO DE RESPONSABILIZAR OS AUTORES DE CRIMES NUCLEARES: ANÁLISE DO CASO GOMES LUND E OUTROS ("GUERRILHA DO ARAGUAIA") VS. BRASIL
}

\section{Eneas Romero de Vasconcelos}

Mestre em Direito e Estado pela Universidade de Brasília (UnB). Pesquisador da Georg-August Universität Göttingen, Alemanha e membro do GlipGö. Promotor de Justiça e professor licenciado da FA7. eneasromero@hotmail.com.

Sumário: Introdução. 1. O direito interno: o direito da ditadura e a anistia brasileira 2. Os direitos humanos internacionais: a ADPF $153 \mathrm{e}$ as obrigações do Brasil perante a Corte IDH. Conclusão. Referências.

RESUMO: Depois do julgamento da ADPF 153 pelo STF (que considerou constitucional a lei de anistia, impedindo a responsabilização penal dos militares) a Corte Interamericana de Direitos Humanos, no caso Araguaia, condenou o Brasil, dentre outras medidas, a responsabilizar criminalmente os autores de crimes nucleares. O presente trabalho estudas ambas as decisões a partir do direito internacional dos direitos humanos.

Palavras-chave: Direitos Humanos. Justiça de transição. Corte internacional. Responsabilidade penal e STF.

\section{INTRODUÇÃO}

O estudo sobre a responsabilidade penal dos autores de crimes nucleares contra os direitos humanos após a substituição de regimes autoritários por regimes democráticos é um tema central na Justiça de Transição (KRITY, 1995 e AMBOS, 2009). No ordenamento jurídico nacional dos países em transição tem sido apresentadas diferentes respostas, como a responsabilização penal plena dos agentes estatais (inclusive com invalidação de leis de anistia ou sua não aplicação), responsabilização penal parcial (com ou sem a instauração de comissões de verdade) e ausência de responsabilização criminal. No Direito Internacional, as cortes internacionais especiais (Tribunal de Nuremberg, Tóquio, Iugoslávia, Ruanda), universais (Tribunal Penal Internacional) e regionais (Corte Interamericana de 
Direitos Humanos e Corte Europeia de Direitos Humanos) têm responsabilizado criminalmente os principais autores de crimes nucleares.

No Brasil, após a ditadura militar, embora tenham sido estabelecidas algumas medidas em favor da vítimas da ditadura e do restabelecimento da verdade, nenhum agente militar da ditadura foi responsabilizado criminalmente pelo cometimento de crimes nucleares. A Lei 6.683/79 anistiou todos os autores, civis ou militares, agentes estatais ou terroristas, de "crimes políticos ou conexos", inclusive "os crimes de qualquer natureza relacionados com crimes políticos ou praticados por motivação política”, praticados entre o período de 2 de setembro de 1961 e 15 de agosto de 1979. Desde o início da sua vigência, a lei tem sido considerada válida, obstaculizando a responsabilização criminal. No ano passado, o Supremo Tribunal Federal do Brasil (STF) decidiu (por maioria de votos), em sede de controle concentrado de constitucionalidade, que a Lei de anistia é constitucional e válida, impedindo a responsabilização penal no direito interno brasileiro.

A Corte Interamericana de Direitos Humanos (Corte IDH), por outro lado, em dezembro de 2010, condenou o Brasil, dentre outros itens, a investigar e responsabilizar crminalmente e aplicar as sanções aos autores de crimes no caso da Guerrilha do Araguaia.

A decisão da Corte IDH opõe-se frontalmente à decisão da mais alta corte do Brasil, composta integralmente por juízes escolhidos e nomeados após o advento da democracia. Desta tensão, entre o direito interno e internacional, surge a seguinte pergunta: pode um tribunal internacional de direitos humanos (no caso, a Corte IDH) aplicar os direitos internacionais humanos para obrigar o Estado parte a responsabilizar penalmente os agentes estatais autores de delitos nucleares em contrariedade à decisão da Suprema Corte do país soberano, que considerou constitucional e válida a anistia ilimitada para autores de referidos crimes?

Para responder a esta pergunta, o presente trabalho tratará: 1) dos crimes cometidos durante a ditadura brasileira e do seu ordenamento jurídico e da aplicação da lei de anistia no Brasil, notadamente no caso da ADPF 153; 2) e, principalmente, dos direitos humanos internacionais para, após análise da jurisprudência da Corte IDH, verificar, de acordo com a doutrina e a jurisprudência internacional, a possibilidade de responsabilização criminal, examinado as exceções preliminares, a anistia, a prescrição e a irretroatividade da lei penal.

\section{DIREITO INTERNO: O DIREITO DA DITADURA E A ANISTIA BRASILEIRA}

Para garantir a impunidade dos crimes cometidos contra subversivos e se manter no poder, a ditadura militar brasileira fez profundas alterações no sistema jurídico, editando atos institucionais, outorgando duas Constituições e 
interferindo em todos os poderes do Estado. Neste contexto, entrou em vigor em 1979 uma lei de anistia ampla, geral e irrestrita, que tem que sido aplicada desde então, impedindo a responsabilização criminal dos autores de crimes nucleares contra os direitos humanos. Em 2010, o STF julgou constitucional e válida a lei de anistia perante a nova Constituição, impedindo a responsabilização criminal.

\subsection{A Ditadura}

Desde o golpe militar de $1^{\circ}$ de abril de 1964 até a posse de um Presidente civil eleito indiretamente (ainda no período de transição) em 15 de março de 1985, o Brasil foi governado exclusivamente por militares escolhidos indiretamente sem participação popular (GASPARI, 2003). Neste período, foram praticados, de modo sistemático e generalizado, crimes nucleares (AMBOS, 2011, p. 219) e outras graves violações contra os direitos humanos (como tortura, homicídio, sequestro, censura, demissões, cassação de direitos políticos etc.) contra os opositores do regime militar. O Brasil, através da Comissão Especial sobre Mortos e Desaparecidos Políticos, reconheceu a existência, durante a ditadura, de cerca de 20 mil torturas, entre 300 e 400 mortos e desaparecidos políticos, centenas de camponeses assassinados e a perda de mandatos e direitos políticos de 4.862 pessoas, conforme relatado pela Comissão sobre Mortes e Desaparecidos Políticos, pela Anistia Internacional e pela Arquidiocese de São Paulo.

\subsection{O direito Da Ditadura}

Para combater os supostamente subversivos e a oposição, entraram em vigor no Brasil neste período diversas normas de exceção, inclusive constitucionais (como os Atos Institucionais e as Constituições outorgadas de 1967/1969), que violaram gravemente diversos direitos humanos.

\subsubsection{Os Militares e o Poder Constituinte: os Atos Institucionais e as CONSTITUições OUTORgadas}

Durante a ditadura, foram outorgadas duas novas Constituições (1967/1969) que centralizaram o poder no executivo federal, eleito indiretamente (BONAVIDES e ANDRADE, 2002), e editados dezessete atos institucionais, atos jurídicos que conferiram poderes constituintes (art. $1^{\circ}$ do AI 5) para os militares ao autorizá-los, dentre outras medidas, a reformar a Constituição, cassar mandatos legislativos, demitir servidores públicos e realizar eleições indiretas para Presidente da República. O mais grave foi o AI 5, o único sem prazo de validade, que suspendeu o habeas corpus contra crimes políticos contra a segurança nacional, proibiu a apreciação judicial dos atos decorrentes de referidos atos e conferiu poderes ao Presidente da República para suspender o Congresso. Ainda que não 
tenha sido autorizada a tortura, o desaparecimento forçado e a execução sumária de opositores, os Atos Institucionais conferiram a base jurídica para permitir referidos atos ao concentrar os poderes nos militares, alijar os demais poderes e suspender direitos e garantais fundamentais.

\subsubsection{Os Poderes na Ditadura}

Embora formalmente houvesse três poderes no Brasil, o Executivo federal passou a controlar os demais, já que, durante a ditadura, os militares tinham poder para escolher governadores e prefeitos, fechar o parlamento e extinguir partidos políticos, cassar mandatos políticos de parlamentares e nomear parlamentares "biônicos". Ao Judiciário, foi excluída a apreciação dos atos decorrentes do AI 5 e de habeas corpus nos crimes contra a segurança nacional e ainda determinada a aposentadoria compulsória de juízes, inclusive de três ministros da Suprema Corte.

\subsubsection{A Lei de Anistia}

Depois de 15 anos de vigência deste Estado de exceção, em que os militares passaram a controlar os demais poderes do Estado e os opositores já haviam sido em sua maioria perseguidos (presos, torturados, exilados, demitidos, cassados, censurados etc.) e intimidados, foi promulgada, em 28.08.1979, com apoio relevante da sociedade civil e papel proeminente da OAB, da ABI e da CNBB, a Lei 6.683, que conferia anistia ampla, geral e irrestrita anistia para os todos os autores de crimes políticos e conexos, bem como com motivação política. A lei de anistia permitiu, por exemplo, a liberdade de opositores do regime presos, o retorno do exílio de opositores do regime e a impunidade absoluta de todos os militares autores de crimes políticos e conexos, inclusive de crimes nucleares contra os direitos humanos.

\subsubsection{Conteúdo e InterpretaÇão da Lei de Anistia Brasileira}

Embora tenha sido discutido o significado e a extensão da Lei de Anistia Brasileira, a interpretação que sempre prevaleceu foi a de que todos os autores e partícipes de crimes políticos, conexos aos políticos, inclusive os praticados com motivação política, seriam beneficiados pela anistia por todos os fatos ocorridos entre 2 de setembro de 1961 e 15 de agosto de 1979. Deste modo, todos os processos criminais e inquéritos policiais instaurados contra militares por crimes praticados neste período foram extintos com fundamento na lei de anistia.

A negociação da lei entre militares, partidos políticos, sociedade civil e outros atores sociais indica que era esta, claramente, a sua finalidade, notadamente em face do desejo dos exilados, presos e torturados de voltarem a 
viver na legalidade no Brasil (DALLARI, 2011)e dos militares de, gradualmente, deixarem o poder sem sofrer sanções. A situação jurídica e política do Brasil na época, porém, impedia um processo realmente democrático na formação da lei, notadamente em face da hipertrofia do executivo e do poder assimétrico dos militares, principais beneficiários posteriores da lei que faziam na defesa do próprio interesse, já que opositores sofreram diversas penalidades penais e extrapenais e os criminosos comuns continuaram sendo punidos pelos mesmos crimes que os militares, ainda que menos graves.

\subsection{A RECEPÇÃo do direito ANTERIOR PELA Constituição de 1988}

Embora a Emenda Constitucional n ${ }^{\circ} 26$ de 27 de novembro de 1985, que convocou uma Assembleia Constituinte, em seu art. $4^{\circ}, \S 1^{\circ}$, tenha ratificado a lei de anistia, com a vigência da nova Constituição todas as normas anteriores precisam ser recepcionadas pelo novo ordenamento, agora democrático, o que pode ser feito através de controle difuso ou concentrado de constitucionalidade por meio de Arguição de Descumprimento de Preceito Fundamental (ADPF).

\subsubsection{Os diReitos FUndamentais na CONSTITUIÇÃo de 1988}

Em oposição à Constituição anterior, a nova Lei Fundamental brasileira estabeleceu a independência e harmonia entre os poderes e conferiu papel central aos direitos fundamentais ( $\operatorname{art} .5^{\circ} \mathrm{da} \mathrm{CF}$ ), centrada na dignidade da pessoa humana, nos termos do art. $1^{\circ}$, III da CF. Estabeleceu, ainda, diversos direitos fundamentais de cunho penal e processual, notadamente a vedação absoluta da tortura (GRECO, 2009, p. 7-40), a imprescritibilidade do crime de racismo (art. $5^{\circ}$, LXII) e da ação de grupos armados contra a ordem constitucional (art. $5^{\circ}$, XLIV) e a insuscetibilidade de graça ou anistia do crime de tortura, tráfico, terrorismo e dos crimes assemelhados aos hediondos.

\subsection{A decisão do STF NA ADPF 153}

Em 21 de outubro de 2008, a OAB, com posterior intervenção de diversos amicus curiae, propôs, perante o STF, uma ADPF para questionar a constitucionalidade da Lei 6.683 perante a nova Constituição (APDF 130/DF, rel. AYRES BRITTO e ADPF 33/PA, relator Gilmar Mendes) e para declarar que a lei de anistia não se estende aos crimes comuns praticados por agentes da repressão contra opositores do regime. O STF decidiu, por maioria de votos $(7 \mathrm{x}$ 2 ), declarar a constitucionalidade da lei de anistia com base nos seguintes argumentos, de acordo com a ementa e o voto do relator, Min. Eros Roberto Grau: a) a Lei de Anistia é válida e abrange todos os crimes políticos e comuns conexos com os políticos, inclusive os cometidos pelos militares; b) a lei de anistia é 
uma lei medida (lei de efeitos concretos) e não pode ser julgada inconstitucional perante a nova ordem; 3) a lei de anistia é anterior à convenção da ONU contra a tortura e outros tratamentos ou penas cruéis, desumanos ou degradantes e à lei brasileira de tortura (Lei 9.455/97) e ao art. $5^{\circ}$ XLIII; 4) somente o legislativo teria legitimidade para reformar a lei de anistia; 5) a lei de anistia foi ratificada pela EC 26/85, emenda convocatória da Constituição e que, portanto, integra a nova ordem constitucional.

Apesar da existência de dois votos dissidentes na ADPF 153, a sentença prolatada em sede de controle de constitucionalidade concentrado pelo STF tem efeito vinculante e eficácia erga omnes (art. 10, § $3^{\circ}$ da Lei 9.882/99) e tornou definitiva (art. 12 da Lei 9.882/99) no âmbito do direito interno a validade da lei de anistia para todos os envolvidos, inclusive os militares autores de crimes nucleares contra os direitos humanos.

\section{OS DIREITOS HUMANOS INTERNACIONAIS: A ADPF 153 E AS obrigaÇões do Brasil PERANTe a CoRTe IDH}

A Lei de Anistia foi considerada válida pelo STF com efeito vinculante e eficácia erga omnes para o direito interno brasileiro. A partir de agora analisaremos se a decisão da República Federativa do Brasil é compatível com o direito internacional, no exercício do controle de convencionalidade, analisando a jurisprudência da Corte IDH e a competência temporal, a anistia, a prescrição e a irretroatividade da lei penal, notadamente em face da decisão da Corte IDH no caso Gomes Lund e outros ("Guerrilha do Araguaia") vs. Brasil.

\subsection{A Jurisprudência da Corte IDH no caso das ditaduras LATINO-AMERICANAS}

No leading case "Barrio Altos vs. Perú" (2001), a Corte IDH decidiu que "são inadmissíveis as disposições de anistia, as disposições de prescrição e o estabelecimento de excludentes de responsabiliade que pretendam impedir a investigação e a sanção dos responsáveis por violações graves aos direitos humanos tais quais a tortura, as execuções sumárias, extralegais ou arbitrárias e os desaparecimentos forçados, todas elas proibidas por contrariar os direitos inderrogáveis reconhecidos pelo Direito Internacional dos Direitos Humanos" (pár. 41).

Posteriormente, nos casos "Almonacid Arellano y otros vs. Chile" (2006), "la Masacre de la Cantuta vs. Peru" (2006) e "la Masacre de la Rochela vs. Colômbia" (2007), a Corte reiterou sua jurisprudência internacional para determinar que os autores de delitos graves contra os direitos humanos internacionais sejam responsabilizados criminalmente, sendo contrárias ao jus cogens e ao direito internacional a existência, no âmbito do direito 
interno, de reservas, anistias, prescrições ou cláusulas de irretroatividade da lei penal para delitos graves contra os direitos humanos, nos termos da convenção interamericana.

\subsection{A Decisão da Corte IDH no Caso Brasileiro}

Em 26 de março de 2009, a CIDH submeteu à Corte IDH, o caso da Guerrilha do Araguaia em face da omissão do Estado brasileiro em estabelecer todas as medidas necessárias para localizar os desparecidos políticos, punir os autores de crimes graves contra os direitos humanos, estabelecer medidas plenas de compensação para as famílias das vítimas e reestabelecer a verdade.

Em sua resposta, o Estado alegou a incompetência ratione temporis, a falta de esgotamento dos recursos internos, a falta de interesse processual dos representantes e a superveniência de causa que instituiria uma quarta instância e, no mérito, solicitou a improcedência. Após o devido processo legal, a Corte, no exercício do controle de convencionalidade das obrigações internacionais assumidas pelo Brasil perante a convenção, reiterou sua jurisprudência anterior e condenou o Estado brasileiro.

Dentre as medidas determinadas, encontra-se a responsabilização criminal dos autores de crimes graves contra os direitos humanos de acordo com o padrão de violações de direitos humanos existentes na época, especialmente do desaparecimento forçado. A corte ressaltou ainda que: "o Estado (brasileiro) não poderá aplicar a Lei de Anistia em benefício dos autores, assim como nenhuma outra disposição análoga, prescrição, irretroatividade da lei penal, coisa julgada, ne bis in idem ou qualquer excludente similar de responsabilidade para eximir-se dessa obrigação, nos termos dos parágrafos 171 a 179 desta sentença” (par. 256, b).

\subsection{O caso Araguaia e o Direito Internacional}

A condenação do Brasil no caso da "Guerrilha do Araguaia" confere maior destaque à justiça de transição no Brasil (SOARES, 2010 e DIMOULIS 2010) e torna necessária uma análise jurídica das questões preliminares (competência temporal e outras) e de mérito (anistia, prescrição e irretroatividade) à luz da jurisprudência e da doutrina internacionais.

\subsubsection{As Exceções Preliminares}

Antes de se analisar as questões de mérito, é necessário que se aprecie perante o direito internacional as exceções preliminares propostas pelo Brasil e rejeitadas pela Corte, já que seu reconhecimento impediria a análise da causa de acordo com o direito convencional. 


\subsubsection{A COMPETÊNCIA TEMPORAL}

Ao reconhecer a competência da Corte IDH pelo Decreto 4.463/2002, o Brasil fez uma reserva para limitá-la temporalmente somente para os fatos posteriores a 10 de dezembro de 1998, o que impediria a análise de fatos ocorridos durante a ditadura militar brasileira, como afirmou o STF na ADPF 153 no voto do relator.

\subsection{O DESAPARECIMENTO FORÇADO COMO CRIME PERMANENTE}

A Corte Interamericana reiterou sua competência para "julgar atos de caráter contínuo durante todo o tempo em que o fato continua" e reconheceu a natureza permanente ou contínua do desaparecimento forçado, que "se inicia com a privação de liberdade da pessoa desaparecida e a subsequente falta de informação sobre seu destino e permanecem até quando não se conheça o paradeiro da pessoa desaparecida e os fatos não tenham sido esclarecidos." (parágrafo 17).

O próprio STF do Brasil, na Extradição 974, deferiu a extradição de argentino responsável pelo crime de sequestro de menor fundamentando a decisão na permanência do delito, já que, em tese, enquanto não desvendado, o crime subsiste, o que afastaria a tese de prescrição. A doutrina internacional sobre desaparecimento forçado e a brasileira sobre sequestro também reconhecem a natureza permanente desses delitos. (AMBOS e BÖHM; p. 255 e SILVA, p. 39.52).

\subsection{A jurisprudência da Corte IDH e o direito internacional}

De todo modo, a Corte IDH, acompanhada da doutrina internacional, vem reconhecendo a sua competência para julgar crimes graves contra a humanidade deduzida dos Tratados Gerais de Direitos Humanos, do Pacto de Direitos Civis e Políticos e da Convenção Interamericana, embora não se possa, segundo AMBOS, derivar daí uma obrigação de responsalizar necessariamente criminalmente em face da existência de outras medidas compensatórias (2010, p. 39).

O costume internacional, os princípios gerais de direito internacional, o jus cogens e a ideia de direito tem justificado, na doutrina e na jurisprudência, a aplicação do direito internacional em caso de violações graves aos direitos humanos, embora o tema seja controverso.

Com o advento do Estatuto de Roma, a jurisprudência do TPI, com amplo apoio da doutrina internacional, tem reconhecido, com fundamento nos tratados combinados e no direito consuetudinário, um dever de responsabilização dos responsáveis por crimes nucleares, até para os países que não fazem parte do tratado, como ocorreu no caso do Sudão e da Líbia. 
A existência de uma jurisdição internacional penal universal, inclusive para países não signatários, passa a servir de fundamento para justificar a atuação dos tribunais internacionais, inclusive da Corte IDH, em caso de crimes nucleares, o que torna sem efeito reservas materiais ou temporais, como seria nula também uma reserva que admitisse a tortura, o genocídio ou a impunidade em relação a quaisquer dos crimes nucleares por sua abosluta incompatibilidade com os direitos humanos internacionais.

O afastamento do limite temporal no caso da Guerrilha do Araguaia, portanto, encontra raspaldo na jurisprudência da Corte Interamericana, no direito internacional e na própria jurisprudência do STF, conforme se subsume da Extradição 974-0 Argentina.

\subsubsection{Outras ExCeções}

Durante o processo, o Brasil arguiu outras exceções e solicitou que o Tribunal: 1) declarasse a sua incompetência em face da ausência de esgotamento dos recursos internos; 2) declarasse a falta de interesse processual dos representanes; 3) reconhecesse a regra da quarta instância.

O Tribunal recusou, integralmente, as exceções com base na sua jurisprudência e no direito internacional, já que: 1) negou o pedido de indeferimento por falta de esgotamento dos recursos internos, que fora, parcialmente, extemporâneo, e reconheceu sua improcedência, assentando que a ADPF não era recurso disponível para as vítimas ou suficiente; 2) a CIDH têm plena legitimidade ativa perante a Corte e as medidas de raparação seriam analisadas no mérito; 3 ) o tribunal analisou o caso de acordo com a convencionalidade, cuja legitimidade decorre do seu reconhecimento enquanto um Tribunal Internacional de Direitos Humanos e não como quarta instância nacional.

\subsubsection{A Anistia}

A anistia, do grego 'amñestia', esquecimento ou oblívio, (MALLINDER, 2009, p. 132) vem sendo usada, há muito tempo, como uma forma de indulgência penal aplicada a crimes, normalmente políticos, cometidos no passado. No Código Penal, a anistia, juntamente com a graça e o indulto, é prevista como causa de extinção da punibilidade (art. 107, II).

\subsubsection{Classificação da Anistia}

A anistia, quanto aos destinatários, pode ser: 1) ampla e geral, abrangendo todos os autores de determinados crimes políticos ou conexos em determinado período e 2) restrita, quando se limita a autores de crime específico, como um crime eleitoral (REALE JUNIOR, 2004, p. 186). Pode, também, ser, quanto aos pressupostos: 1) condicional, quando impõe condições, como a entrega 
das armas, ou 2) incondicional, quando o destinatário não está obrigado a cumprir nenhum dever de agir para se beneficiar da anistia (REALE JUNIOR, 2004, p. 186). De acordo com a autoria, a anistia pode classificar-se em: 1) anistia stricto sensu, quando autor da regra de anistia e o seu destinatário são pessoas diversas; 2) autoanistia, quando o autor da norma é o principal beneficiário da mesma.

CARVALHO FILHO classifica a anistia em: 1) geral ou absoluta, por ser irrestrita e incondicionada e 2) parcial, que pode ser: 2.1) condicionada ao implemento de determinadas condições e 2.2 restrita, por se limitar a determinados crimes, indivíduos ou grupos ou classes de indivíduos (1958, p. 126).

\subsubsection{A Anistia na Justiça de Transição}

Tradicionalmente utilizada como uma medida de concórdia e compaixão, a anistia vem sendo adotada recentemente no contexto de sociedades em transição de um estado autoritário para um estado democrático, com maior ou menor amplitude, com as mais diversas motivações, podendo servir para:

alleviating internal pressure; promoting peace and reconciliation; responding to internal pressure; adehering to cultural or religious traditions; providing reparations; encouraging exiles to return; and protecting state agents from prosecution. (MALLINDER, 2009, p. 133)

Para o nosso estudo, é relevante a noção de anistia como forma de garantir a paz e a reconciliação dentro da justiça de transição. Neste contexto, é útil a classificação da anistia em 1) blanket amnesties, anistia geral ou absoluta, que é irrestrita e incondicionada; 2) anistias parciais: 2.1) restritas a determinadas pessoas ou grupos de pessoas; e 3) condicionadas a determinadas medidas como a reparação, responsabilização e restabelecimento da verdade (através de comissões de verdade, e. g.).

\subsubsection{A validade da Anistia na Justiça de Transição}

As anistias absolutas, conhecidas como anistias amnésicas, por ocasionarem o total 'esquecimento' das atrocidades do passado são amplamente rechaçadas na doutrina e na jurisprudência internacionais por serem: 1) inadmissíveis nos casos de tortura; 2) contrariarem os tratados, os costumes internacionais e o próprio direito internacional; 3 ) serem inadmissíveis em crimes nucleares (AMBOS, 2010, p. 174).

A autoanistia tem sido utilizada como forma de anistiar de modo absoluto, irrestrito e incondicional os principais agentes violadores dos direitos humanos em ditaduras. Neste particular, a Corte IDH construiu sólida jurisprudência contra as autoanistias latino-americanas por contrariarem a Convenção 
Interamericana de Direitos Humanos e o direito internacional, o que foi feito também pelo Tribunal Europeu de Direitos Humanos (Abdülsamet Yaman vs. Turkey, par. 55).

As anistias condicionadas somente têm sido reconhecidas, na Justiça de transição, caso atendam a condições mínimas de restabelecimento da paz, da verdade e da justiça. A doutrina vem procurando criar critérios mínimos para o reconhecimento da juridicidade de uma anistia parcial, como uma comissão de verdade efetiva, limitações materiais (exclusão de crimes nucleares) e pessoais (exclusão dos líderes). De todo modo, deve-se submeter ainda a um exame de sua legalidade através de uma análise do princípio da proporcionalidade.

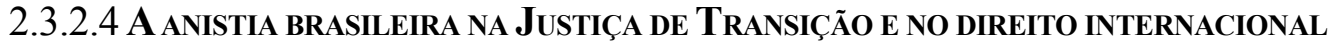

No caso brasileiro, a Lei 6.683 concedeu uma autoanistia, geral e irrestrita, que beneficiou, sem limitações, todos os agentes estatais autores de crimes nucleares, inclusive os líderes da repressão, sem impor quaisquer condições.

A autoanistia brasileira (promulgada durante um estado de exceção em que os Poderes do Estado eram controlados pelos principais violadores e beneficiários da lei) garantiu a impunidade plena dos militares que, ao contrário dos opositores (que foram perseguidos, mortos, presos, torturados, censurados etc.) e dos criminosos comuns (como os autores de outros crimes, inclusive de pequena monta, como furtos de pequeno valor), jamais sofreram qualquer sanção.

Embora tenha sido reconhecida válida no direito interno (a despeito da não vigência do Estado de Direito e da violação do princípio da igualdade, já que somente os militares nunca foram punidos, e da dignidade da pessoa humana), a lei de anistia brasileira não encontra respaldo no direito convencional.

A anistia brasileira contraria direito internacional por violar: 1) o dever de responsabilizar criminalmente os crimes graves contra a humanidade e os crimes nucleares; 2) os tratados internacionais; 3) o costume e os princípios gerais de direito internacional; 4) o jus cogens e a própria ideia de direito.

No caso dos crimes nucleares, a eventual admissibilidade de anistias absolutas é contrária à própria finalidade do Tribunal, pois, como observou AMBOS:

In fact, it is difficult to explain that an institution created to avoid impunity, should promote it by accepting amnesty; indeed, this would go against the telos of the ICC. (2009, p. 70)

Com efeito, a concessão de anistias absolutas para crimes nucleares não encontra âmparo na jurisprudência de direitos humanos (especialmente da Corte Interamericana) e na doutrina internacionalista. 


\subsubsection{A PRESCRIÇÃo}

A prescrição "põe fim à ação ou à pena, pelo decurso do tempo" (CARVALHO FILHO, 1958, p. 212) e se fundamenta na preservação da segurança jurídica. No Código Penal brasileiro, a prescrição, juntamente com a decadência e a perempção, é prevista como causa de extinção da punibilidade (art. 107, IV).

O prazo prescricional máximo previsto pelo Código Penal brasileiro é de 20 anos (art. 109, I do CP). Como os fatos consumados na época da ditadura ocorreram há mais de 20 (vinte) anos, "todas as ações penais estão prescritas", segundo o ministro Peluso na ADPF 153.

Ademais, a Constituição brasileira prevê a imprescritibilidade apenas do crime de racismo (art. $5^{\circ}$, LXII) e da ação de grupos armados contra a ordem constitucional (art. $5^{\circ}$, XLIV e HC 82.424/RS, STF). No direito internacional, o Brasil não ratificou os tratados que reconhecem a imprescritibilidade dos crimes de guerra e dos crimes contra a humanidade ou qualquer outro tratado em que se reconheça expressamente a imprescritibilidade (Voto do ministro Peluso na ADPF 153, STF).

\subsubsection{A SUSPENSÃo da PRESCRIÇão}

A doutrina e a jurisprudência de diversos países têm reconhecido, porém, a existência de causas suspensivas da prescrição para os crimes graves contra os direitos humanos cometidos por agentes de ditaduras fundadas: 1) na inexistência de Estado de Direito (rule of law) como hipótese de suspensão da prescrição, já que na vigência de um estado autoritário é inviável a responsabilização dos criminosos de Estado; 2) na aplicação de lei de anistia, durante o período em foi considerada válida, como causa de suspensão da prescrição.

\subsubsection{A IMPRESCRITIBILIDADE DOS CRIMES NUCLEARES}

Antes da criação do TPI, já se reconhecia, no direito internacional, a imprescritibilidade dos crimes graves contra a humanidade, como vinha decidindo a Corte Interamericana, especialmente em casos de tortura. Com o advento do Tribunal Penal Internacional, responsável por julgar os crimes nucleares contra os direitos humanos (o genocídio, os crimes de guerra e os crimes contra a humanidade) o instituto da prescrição contradiz a própria finalidade de uma justiça internacional penal criada apenas para punir os mais graves crimes contra os direitos humanos.

A decisão da Corte IDH ao declarar imprescritíveis os graves crimes contra os direitos humanos de acordo com a convenção interamericana encontra, portanto, fundamento no direito internacional e o Brasil, enquanto Estado parte, tem a obrigação de respeitar a decisão da Corte Internacional. 
Poderia recorrer-se, ademais, como fundamento último para a imprescritibilidade, à fórmula de Radbruch (SWENSSON JUNIOR; 2010, p. 47-54), mas, no atual estágio de desenvolvimento do direito internacional penal, a imprescritibilidade dos crimes nucleares encontra fortes argumentos no direito positivo, estando os Estados obrigados a respeitar os direitos humanos internacionais.

\subsubsection{A Irretroatividade da Lei Penal}

O princípio jurídico da irretroatividade da lei penal (nullum crime, nulla poena sine praevia lege), previsto pela Constituição brasileira (art. $5^{\circ}$, XXXIX), é apontado como um importante obstáculo para a responsabilização criminal dos militares autores de crimes nucleares ocorridos durante a ditadura.

O desaparecimento forçado, porém, ainda continua, em tese, a ocorrer, e se aplica a ele o Código Penal atualmente vigente no Brasil, que tipifica o fato como sequestro.

A responsabilização penal por fatos ocorridos na ditadura não implica, na grande maioria dos casos, na criação de novos tipos penais, já que os principais crimes contra os direitos humanos praticados pela ditadura, como homicídio, lesão corporal, maus-tratos, estupro e atentado ao pudor, dentre outros, eram tipificados como crimes pelo Código Penal da época, ainda vigente com algumas alterações.

O fato, na época, era previsto como típico e antijurídico e o que impediu a responsabilização dos militares foi a existência de um Estado de Exceção (em que os militares controlavam os Poderes do Estado) e a aplicação da lei de anistia, que, mesmo na democracia, foi reconhecida como causa de extinção da punibilidade.

A decisão da Corte Interamericana que declarou inexistente, nula ou sem efeito a anistia brasileira negou vigência desde a origem, perante o direito internacional, a uma causa de extinção de punibilidade. Por conseguinte, o fato típico, antijurídico e culpável permanece sendo punível de modo semelhante ao que ocorreria caso fosse declarada a inconstitucionalidade com efeito ex tunc de uma causa de extinção da punibilidade no direito interno.

\section{Conclusão}

Durante a ditadura brasileira, as gravíssimas violações aos direitos humanos, inclusive os crimes contra a humanidade, foram acompanhadas pela instituição de um direito de exceção e pela hipertrofia do poder Executivo controlado pelos militares em detrimento dos demais poderes. A Lei de Anistia, ainda que contasse com apoio da sociedade civil, foi elaborada neste contexto e serviu para beneficiar os militares, que ficaram impunes pelos crimes que cometeram. 
A declaração de constitucionalidade da Lei de Anistia pelo STF, durante a vigência do Estado de Direito, pode ter validade no âmbito interno, mas não vincula os tribunais internacionais.

A decisão do caso "Gomes Lund e Outros vs. Brasil" da Corte IDH, ao determinar a obrigação do Brasil para responsabilizar criminalmente os agentes da repressão autores de crimes graves contra os direitos humanos e declarar contrárias ao direito internacional os limites temporais, a anistia, a prescrição e a irretroatividade da lei penal para o caso Araguaia encontram fundamento na doutrina internacional e na jurisprudência da própria Corte e de outros tribunais de direitos humanos.

Como Estado parte da Corte IDH, o Brasil deverá cumprir a decisão e adequar o seu direito interno ao direito convencional, sob pena de infringir o direito internacional dos direitos humanos (ALFONSO, p. 65-68 e DAMASKA, p. 329-365).

\section{REFERÊNCIAS}

ALFONSO, César. La obligatoriedad de las decisiones de la Corte Humanos desde la perspectiva de distintos países de América del Sur. In: AMBOS, Kai, MALARI$N O$, Ezequiel e $E L S N E R$, Gisela (ed). Sistema Interamericano de Protección de los derechos humanos $\mathbf{Y}$ derecho penal internacional. Montevideo: Georg-August-Univertät-Göttingen/Konrad Adenauer Stifung, p. 63-79.

ALMQVIST, Jessica; Espósito, Carlos (coord.). Justicia transnacional en Iberoamérica. Madrid, Centro de Estudios Políticos y Constitucionales, 2009.

AMBOS, Kai. Internationales Strafrecht. Strafanwendungsrecht - Völkerstrafrecht - Europäisches Strafrecht. 3. Auflage. München: Verlag C. H. Beck, 2011

. O Marco Jurídico da Justiça de Transição. In: SOARES, Inês Virgínia P. e ZILLI, Marcos. Anistia, Justiça e Impunidade. Reflexões sobre a Justiça de Transição no Brasil. Belo Horizonte: Editora Fórum, 2010.

AMBOS, Kai e BÖHM, María Laura. La desaparición forzada de personas como tipo penal autónomo. In: Desaparición forzada de personas. Análisis comparado e internacional. Bogotá: Editorial Temis S. A., 2009, p. 195-255.

AMBOS, Kai et. al. (eds.). Building a Future on Peace and Justice: Studies on Transnational Justice, Peace and Development. Berlin, Heidelberg: Springer-Verlag, 2009.

DALLARI, Dalmo de Abreu. Anistia: Esquecimento legal e memória de fato, Disponível em: http://www2.fpa.org.br/o-que-fazemos/memoria-e-historia/ exposicoes-virtuais/dalmo-dallari, (última busca em 10.06.11). 
BONAVIDES, Paulo. Curso de Direito Constitucional, 11. ed. São Paulo: Malheiros, 2001.

BONAVIDES, Paulo \& ANDRADE, Paes de. História Constitucional do Brasil. Brasília: OAB editora, 2002.

BRUNO, Anibal. Direito Penal. Parte Geral. Tomo $3^{\circ}$. Pena e Medida de Segurança. 3. Ed. Rio e São Paulo, Forense, 1967.

CARVAlHO FILHO, Aloysio de. Comentários ao Código Penal. Vol. IV. 4. ed. Rio de Janeiro, Forense, 1958.

DAMASKA, Mirjan, What is the Point of International Criminal Justice?, Chicago-Kent Law Review 83 (2008), 329-365.

DIMOULIS, Dimitri, MARTINS, Antonio, SWENSSON JUNIOR, Lauro Joppert e NEUMANN, Ulfrid. Justiça de transição no Brasil. São Paulo, Editora Saraiva, 2010.

ESER/SIEBER/ARNOLD (Hrsg.). Strafrecht in Reaktion auf Systemunrecht. Vergleichende Einblicke in Transtionsprozesse. Teilband 13. Brasilien. Berlin: Duncker \& Humboldt, 2009.

KRITY, Neil J, editor. Transitional Justice. How emergin democracies reckon with former regimes. Washington, D.C.: United States Institute of Peace Press, 1995. Contents: v. 1. General considerations. V. 2. Countrz Studies. V. 3. Laws.

GASPARI, Elio. O sacerdote e o feiticeiro: a ditadura derrotada. São Paulo: Companhia das Letras, 2003.

. A ditadura envergonhada. São Paulo: Companhia das Letras, 2003. . A ditadura escancarada. São Paulo: Companhia das Letras, 2003.

GRECO, Luís e SCHÜNEMANN, Bernd. As regras por trás da exceção: reflexões sobre a tortura nos chamados "casos de bomba-relógio" e comentário. In: Revista Brasileira de Ciências Criminais. São Paulo Ano 17, n. 78, Revista dos Tribunais, p. 7-40, mai/jun de 2009.

HERNANDEZ, Salvador A. Millaleo. Strafrecht in Reaktion auf Systemunrecht in Chile. In: Eser/Sieber/Arnold (Hrsg.). Strafrecht in Reaktion auf Systemunrecht. Vergleichende Einblicke in Transtionsprozesse. Teilband 11. Berlin: Duncker \& Humboldt, 2007.

PETÉ, Stephen und PLESSIS, Max du. Repairing the Past? International Perspectives on Reparation for Gross Human Rights Abuses. Intersentia: Antwerpen und Oxford, 2007.

MALLINDER, Louise. Exploring the Practice of States in Introducing Amnesties. In: $A M B O S$, K. et. al. (eds.). Building a Future on Peace and Justice: Stud- 
ies on Transitional Justice, Peace and Development. Berlin and Heidelberg: Springer-Verlag, 2009, p. 127-171.

PRADO, Luís Regis. Curso de Direito Penal Brasileiro. Parte Geral. Arts. $1^{\circ}$ a 120. Vol. 1. 9. ed. São Paulo, RT, 2010.

QUEIROZ, Paulo. Direito Penal. Parte Geral. 2. ed. São Paulo: RT, 2005.

REALE JUNIOR, Miguel. Insituições de Direito Penal. Vol. II. W. ed. Rio de Janeiro, Forense, 2004.

SOARES, Inês Virgínia Prado e KISHI, Sandra Akemi Shimada (coord.). Memória e verdade. A Justiça de Transição no Estado Democrático de Direito. Belo Horizonte: Editora Fórum, 2009.

SOARES, Inês Virgínia P. e ZILLI, Marcos. Anistia, Justiça e Impunidade. Reflexões sobre a Justiça de Transição no Brasil. Belo Horizonte: Editora Fórum, 2010.

SILVA, Pablo Rodrigo Alflen. Informes Nacionales. Brasil. In: AMBOS, Kai (coord). Desaparición forzada de personas. Análisis comparado e internacional. Bogotá: Editorial Temis S. A., 2009, p. 39-52.

SWENSSON JUNIOR, Lauro Joppert. Anistia Penal. Problemas de Validade da Lei de Anistia Brasileira (Lei 6.683/79). Curitiba, Juruá, 2009.

ZAFFARONI, Eugenio Raúl e PIERANGELI, José Henrique. Manual de Direito Penal. Parte Geral. 5. ed. São Paulo, RT, 2004.

\section{THE GOMES LUND AND OTHERS VS. BRAZIL CASE: CONSTITUTIONAL ASPECTS}

Abstract: After the judgment from ADPF 153 by the Brazilian Supreme Court (which found constitutional the amnesty law for the military, avoiding criminal responsibility) the Interamerican Court for Human Rights, in case Araguaia, decided that Brazil must punish militaries for core crimes. The present work studies both decisions and the international human rights.

Keywords: Human Rights. Transitional justice. international courts, criminal responsibility. Supreme Court. Brazil.

Data de recebimento: nov/2010 - Data de aprovação: jan/2011 